NBER WORKING PAPER SERIES

\title{
HOW DOES STATE-LEVEL CARBON PRICING IN THE UNITED STATES AFFECT INDUSTRIAL COMPETITIVENESS?
}

\author{
Brendan J. Casey \\ Wayne B. Gray \\ Joshua Linn \\ Richard Morgenstern \\ Working Paper 26629 \\ http://www.nber.org/papers/w26629
NATIONAL BUREAU OF ECONOMIC RESEARCH
1050 Massachusetts Avenue
Cambridge, MA 02138
January 2020

The opinions and conclusions expressed are those of the authors and do not reflect those of the US Census Bureau or the National Bureau of Economic Research. This research was performed at a Federal Statistical Research Data Center under FSRDC Project Number FSRDC1191. All results using Census data have been reviewed to ensure that no confidential information is disclosed. The authors thank the Resources for the Future Carbon Pricing Initiative for supporting the research.

NBER working papers are circulated for discussion and comment purposes. They have not been peer-reviewed or been subject to the review by the NBER Board of Directors that accompanies official NBER publications.

(C) 2020 by Brendan J. Casey, Wayne B. Gray, Joshua Linn, and Richard Morgenstern. All rights reserved. Short sections of text, not to exceed two paragraphs, may be quoted without explicit permission provided that full credit, including $\odot$ notice, is given to the source. 
How Does State-Level Carbon Pricing in the United States Affect Industrial Competitiveness? Brendan J. Casey, Wayne B. Gray, Joshua Linn, and Richard Morgenstern NBER Working Paper No. 26629

January 2020

JEL No. Q4,Q52,Q58

\begin{abstract}
$\underline{\text { ABSTRACT }}$
Pricing carbon emissions from a jurisdiction could harm the competitiveness of local firms, causing the leakage of emissions and economic activity to other regions. Past research concentrated on national carbon prices, but the impacts of subnational carbon prices could be more severe due to the openness of regional economies. Focusing on subnational carbon pricing in the United States, we specify a flexible model to capture competition between a plant in a state with carbon pricing and plants in other states or countries. We estimate model parameters using confidential plant-level data from 1982-2011 and simulate the effects of regional carbon prices covering the Northeast and Mid-Atlantic (regions that currently cap carbon emissions from the electric sector) on manufacturing output, employment, and profits. Importantly, we model industry mix within a state or region, not simply energy price differences. A carbon price of $\$ 10$ per metric ton reduces employment in the regulated region by 2.7 percent, and raises employment in nearby states by 0.8 percent; the effects on output and profits are broadly similar. National employment falls just 0.1 percent, suggesting that domestic plants in other states as opposed to foreign facilities are the principal winners from state or regional carbon pricing.
\end{abstract}

\author{
Brendan J. Casey \\ ICF \\ 9300 Lee Highway \\ Fairfax, VA 22031 \\ brendan.casey@icf.com \\ Wayne B. Gray \\ Department of Economics \\ Clark University \\ 950 Main Street Worcester, \\ MA 01610 and NBER \\ WGRAY@CLARKU.EDU
}

\author{
Joshua Linn \\ Resources for the Future \\ 1616 P St NW \\ Washington, DC 20036 \\ linn@rff.org \\ Richard Morgenstern \\ Resources for the Future \\ 1616 P Street, NW \\ Washington, DC 20036 \\ morgenstern@rff.org
}




\section{Introduction}

Increasingly, carbon prices vary across jurisdictions that trade goods with one another. This phenomenon exists in the United States and the European Union, where most countries participate in the EU Emissions Trading System. Many individual nations also have policies that effectively cause carbon prices to differ from prices elsewhere in Europe and international prices. In the United States, several states are considering adopting a carbon price (either an emissions tax or cap) or strengthening existing carbon prices. Since 2009, the Northeast has capped carbon emissions from the electricity sector. And California has capped most state-wide carbon emissions since 2012. Other states are considering introducing a carbon price for electricity generation, transportation, and other sectors. ${ }^{2}$ The abrupt change in US climate policy between the Obama and Trump administrations has likely contributed to states' growing interest in pricing carbon as a substitute for federal policy.

By design, pricing carbon emissions raises energy prices in accordance with the carbon content of the energy. The economic cost of the resulting price increases has been a contentious issue for states and regions considering carbon pricing because manufacturing plants located in jurisdictions with such policies are potentially put at a competitive disadvantage, which could reduce their output, employment, and profits. Moreover, reduced output in regions with carbon pricing may be offset by increased output elsewhere, resulting in emissions leakage - a situation in which net global emissions decline by less than emissions reduction in the carbon pricing region. Adverse competitiveness effects of a carbon price thus can lead to broader negative economic and environmental consequences.

A large body of literature examines the potential for international leakage - in which case a country (or set of countries) imposes a carbon price, causing emissions to flow to countries without carbon pricing policies. A central insight of this literature is that the extent of leakage

\footnotetext{
${ }^{2}$ For example, as of late 2018, Oregon was considering pricing carbon and linking its program with California's, and many states in the Mid-Atlantic and Northeast were also considering the expansion of the existing Regional Greenhouse Gas Initiative (RGGI) that covers electricity sector emissions.
} 
depends on the degree of competition between firms in countries that impose a carbon price and those that do not. ${ }^{3}$

Given the trend in state-level US climate policy, we examine industrial sector leakage from states that adopt a carbon price. Applying the conclusions from the leakage literature to statelevel carbon pricing suggests that the geographical shifts in economic activity from state or regional policies could be greater in magnitude than those from a national carbon price. Electricity accounts for less than 2 percent of total US manufacturing costs. However, for aluminum, chemicals, cement, and certain other industries the cost share is considerably higher-suggesting proportionately larger negative effects of higher electricity prices. Plants also combust fuels directly and consume electricity and fuels indirectly that are embodied in their production materials.

Moreover, states export a large share of their manufacturing output, making state-level manufacturing output sensitive to competition from other states and countries. In 2012, about 65 percent of manufacturing output (by value) was shipped more than 100 miles and about 65 percent of output was shipped to another state or country. The domestic competitive pressures faced by manufacturing plants in a particular state suggest that even a modest carbon price applied to only that state could be costly and lead to a substantial decrease in output and employment, as well as emissions leakage. In contrast, because a national carbon price would affect energy prices by similar amounts for all US plants, the effects on competitiveness of US plants would be relatively smaller as long as domestic competition is stronger than international competition.

State policymakers could take steps to reduce these adverse effects on competitiveness for the manufacturing sector. In particular, states could use tax revenue (or in the case of a cap-andtrade program, allocate emissions credits rather than auction them) to compensate firms and reduce the likelihood of employment and output losses and the risk of emissions leakage. For example, to reduce leakage from its cap-and-trade program, California allocates emissions credits to certain industries based on their energy intensity and exposure to international

\footnotetext{
${ }^{3}$ For example, see Fowlie, Reguant, and Ryan (2016); Fischer and Morgenstern (2009); Fischer and Fox (2012); and Boehringer, Fischer, and Rosendahl (2010).
} 
competition. However, using the tax or auction revenue this way has an opportunity cost because that revenue could be used for other public purposes, such as infrastructure investments. Clearly, there are costs to over or undercompensating the manufacturing sector, and policymakers need to know the magnitude of the adverse competitiveness effects of state or regional carbon prices.

Despite the importance of these issues in US policy debates, the existing literature provides little insight into the effects of a state's carbon price on economic activity in the state and emissions leakage to other regions. The few existing studies focus on national carbon pricing. Using national-level data, Aldy and Pizer (2015) estimate the effects of energy prices on manufacturing employment. They use their results to infer the effects of a hypothetical national carbon price, finding that a carbon tax of $\$ 15$ per ton would increase net imports by up to 0.8 percent for the most energy intensive industries. Because they use national-level data, their results reflect competition among US and international manufacturing plants. The effects of a statewide carbon price depend not only on US and international competition, but also on competition among states. Although Kahn and Mansur (2013) estimate the effect of electricity prices on employment by comparing adjacent counties, their analysis does not directly translate to a statewide carbon price, which would affect energy prices at the state and not the county level. The general equilibrium literature (e.g., Boehringer, Fischer, and Rosendahl 2010; Fischer and Fox 2012; and Adkins et al. 2012) lacks the geographic resolution necessary to address this question.

Building on our previous work (Gray, Linn, and Morgenstern 2016), we quantify the competitiveness effects of state-level carbon pricing. Specifically, we estimate the effects of a state or regional carbon price on manufacturing output, employment, and profits-both for those plants that face carbon prices and for other domestic plants not subject to carbon pricing. To accomplish this, we develop a general model linking a manufacturing plant's output, employment, and profit with the energy prices it faces as well as the prices faced by its competitors. We estimate the model parameters using confidential plant-level data from a 30year panel, and use the model to consider particular examples of carbon pricing in the Northeast 
and Mid-Atlantic under the assumption that the carbon price is passed through into energy prices faced by the plant. ${ }^{4}$

More specifically, the model links plant-level outcomes to energy prices, where the outcomes include employment, output, value added, and operating profits. We decompose the effect of a regional carbon price on a plant's outcome into two channels: a) the change of the national average outcome for the corresponding industry; and b) the deviation in the plant's outcome from that national average outcome. We estimate the first channel using an approach similar to Aldy and Pizer (2015).

Estimating the second channel is the primary literature contribution of our empirical analysis. This empirical component contains several features that make it particularly suitable for the analysis of state-level carbon pricing. First, and most importantly, we control separately for the energy prices a plant faces and the energy prices faced by competing plants in other states and countries. This allows us to show transparently how carbon pricing in one state affects outcomes in that state and others. Second, we allow the effects of energy prices on output and employment to vary across industries and in a flexible manner. We partially relax assumptions that many other studies (e.g., Linn 2008, 2009; and Aldy and Pizer 2015) have imposed on the relationships between a plant's energy cost share and the elasticity of its output and employment to energy prices. Third, because some states (e.g., California) price carbon emissions from electricity and fuels whereas other states (e.g., New York) price carbon only for electricity, the model includes separate measures of electricity and fuels prices. In contrast, some empirical studies, such as Aldy and Pizer (2015), aggregate electricity and fuels. Finally, the model accounts for the energy embedded in materials inputs and also for demand and labor cost shocks. This model extends the work of Gray, Linn, and Morgenstern (2016) in several ways: including all industries rather than selected energy-intensive, trade-exposed industries in the analysis; including all fuels rather than just natural gas; and controlling for indirect energy use. These advances make it possible to evaluate a wide range of actual or hypothetical state carbon prices.

\footnotetext{
${ }^{4}$ Ganapati, Shapiro, and Walker (2017) estimate the pass-through of energy prices to marginal costs and output prices. Our assumption on pass-through regards the pass-through of the carbon price to energy prices, and not output prices for the manufacturing plants. Fabra and Reguant (2014), among others, provide evidence on full pass-through of a carbon price to energy prices.
} 
We use plant-level Census data from 1982-2011 to estimate a short-run (annual) reducedform model of energy prices and the economic outcomes of interest (employment, output, value added, and operating profits). The parameter estimates largely conform to intuition. The effects of a plant's own energy prices on its output, employment, and profits are generally negativereflecting the decrease in competitiveness for a plant that faces higher energy prices, all else equal. The effects of competing plants' energy prices are typically positive for the same reason, because an increase in a competitor's energy prices is advantageous to other plants. Energyintensive industries are typically more adversely affected by energy prices than other industries.

The model is quite general and could be applied to consider any state or regional carbon price in the United States. As an application, we use the model to simulate the effects of carbon prices in the Northeast and Mid-Atlantic. We focus on these regions for two main reasons. First, the Regional Greenhouse Gas Initiative (RGGI) has capped carbon emissions from the electricity sector in the Northeast since 2009. New England and much of the Mid-Atlantic currently belong to RGGI. ${ }^{5}$ Carbon prices have typically been low, at around $\$ 2$ per ton of carbon dioxide $\left(\mathrm{CO}_{2}\right)$, but recent changes to the program may cause emissions prices to increase substantially in the coming years. ${ }^{6}$ Second, several states have considered joining RGGI, and political opposition has pointed to the potential adverse effects on manufacturing.

We define two carbon price scenarios, relative to a no-policy baseline. The first scenario includes a carbon price of $\$ 10$ per ton of $\mathrm{CO}_{2}$ for the current RGGI states. The second scenario assumes that Pennsylvania and New Jersey join the program, and we compare this scenario against the first scenario. We chose these states because they border the RGGI region and have previously belonged to RGGI or have considered joining; both states have substantial levels of manufacturing employment. We also consider higher carbon prices and carbon prices that affect electricity and fuels. The additional scenarios are motivated by the fact that some RGGI states have considered expanding their carbon price to include fuels used by the manufacturing sector.

\footnotetext{
${ }^{5}$ More specifically, RGGI includes Connecticut, Delaware, Maine, Maryland, Massachusetts, New Hampshire, New York, Rhode Island, and Vermont. New Jersey initially participated but dropped out in 2012.

${ }^{6}$ In 2017, RGGI states adopted an emissions containment reserve. If the emissions price falls below specific target levels, participating states may withhold allowances from circulation, which would put upward pressure on the allowance price.
} 
Given the estimation results, we expect several patterns to emerge in the simulations. First, the RGGI carbon price on electricity should reduce manufacturing employment, output, and profits in RGGI states, and increase these outcomes in neighboring states. Second, these effects should be larger in magnitude for energy-intensive industries than for other industries. Third, expanding RGGI should reduce employment, output, and profits in the states that join RGGI, and increase those outcomes in states close to the expanded RGGI region in our analysis.

Our results confirm these expectations. Specifically, a RGGI carbon price of $\$ 10$ per ton of $\mathrm{CO}_{2}$ reduces employment by 2.7 percent in RGGI states. The carbon price has similar effects on output and profits. A RGGI carbon price increases employment, output, and profits in neighboring states by 0.8 percent on average, suggesting a substantial shift of economic activity outside of RGGI. National employment falls by just 0.1 percent, suggesting that most of the adverse economic effects on the RGGI states occur due to domestic rather than international competition. Expanding the carbon price to include additional states reduces the employment, output, and profit losses for the original RGGI states. This suggests that adverse economic effects and leakage within the United States are highly sensitive to the geographic extent of the carbon price.

\section{Empirical Strategy}

\subsection{Decomposing the Effects of a Regional Carbon Price}

The objective of the empirical model is to characterize the reduced-form relationship between energy prices and various plant-level outcomes: value of shipments; value added (defined as the difference between the value of shipments and the sum of energy and materials costs); employment; and operating profits (defined as the difference between the value of shipments and the sum of energy, materials, and labor costs).

As noted in the introduction, Aldy and Pizer (2015) estimate the effects of national average energy prices on national employment, and they use the results to make inferences on the effects of a hypothetical national carbon price on national employment. One expects that a national carbon price would affect employment in a given industry in the same direction across all regions of the country, although the magnitude of the effect could vary across regions due to regional differences in energy intensity or other factors. In our context, by contrast, a regional 
carbon price would not have such uniform effects. A carbon price in the Northeast, for example, could reduce employment in the Northeast but increase employment in other regions. The effects of regional carbon prices are more likely to vary in direction across regions with a greater degree of competition among plants across regions.

This possibility suggests decomposing into two terms the effects of a regional carbon price on the outcomes of plant $i$ in industry $j$. The first term is the effect of the regional carbon price on the national average of that outcome for the industry, $\Delta y_{j}$. This term captures competition among domestic and foreign plants in the industry. If plants in the industry compete closely with foreign plants, the national average effect should be negative - but if competition is purely domestic, the national average effect could be zero.

The second term in the decomposition is the plant's deviation from the corresponding national average, $\Delta y_{i j}$. This term captures domestic competition. If the region imposes a carbon price, the deviation should be negative, as the carbon price causes plants in the region to be less competitive compared to other domestic plants. If the region does not impose a carbon price, the deviation should be positive because the plants in the region are more competitive compared to plants in the regulated region.

Aldy and Pizer (2015) estimate the first term in this decomposition. Identifying the second term is the main focus of our empirical analysis, as discussed below.

\subsection{Estimating Deviations from National Average Effects}

This subsection describes the short-run econometric model that links a manufacturing plant's economic activity to the energy prices it faces and the energy prices of its competitors. The effects of energy prices on an individual manufacturing plant depend on where the plant is located. For example, suppose Massachusetts adopts a carbon price that raises energy prices, and that no other states adopt a carbon price. In that case, the energy costs of plants located in Massachusetts increase relative to competing plants elsewhere. In contrast, for a plant located outside the Bay State, the energy prices it faces do not change, while the prices paid by its competitors increase. The increase in energy prices in Massachusetts, therefore, can create a competitive advantage for plants located outside the state. 
For either a plant in Massachusetts or a plant outside the state, we can express output, employment, value added, or profits $(y)$ as a function of the energy prices faced by either plant and the energy prices of its competitors:

$\ln (y)=\beta_{1} \mathrm{~s} * \ln (p)+\beta_{2} s * \ln \left(p_{R}\right)$

where $s$ is the cost share of energy, $p$ is the energy price the plant faces, and $p_{R}$ is the energy price faced by plants in other states. The energy cost share is multiplied by the energy price because a given energy price increase should have a greater effect on the outcomes for energyintensive industries than for other industries. We expect $\beta_{1}$ to be negative because a plant facing higher costs should produce less output and have lower profits, and these negative effects should increase in magnitude with the cost share. In principle, if energy and labor are strong enough substitutes, the coefficient could be positive for employment.

In the case where output is on the left-hand side of Equation (1), this particular functional form (in which we interact the cost shares with the energy prices) represents a generalization of a Cobb-Douglas production function. If the plant has a Cobb-Douglas production function, the output would be directly proportional to the interaction of the cost share with the price, and $\beta_{1}$ would equal -1 .

The parameter $\beta_{2}$ should be positive because an increase in the energy prices of competing plants makes the plant more competitive relative to those plants. For example, a Massachusetts energy price increase would increase the competitiveness of plants outside the state that compete with Massachusetts plants, causing their $y$ to increase. Note that we could express the outcome variable as a function of the price of energy faced by the Massachusetts plant relative to the price of energy in other states (i.e., $p / p_{R}$ ), which would be equivalent to setting $\beta_{1}=-\beta_{2}$ in Equation (1).

To arrive at the estimating equation, we relax a number of assumptions embedded in Equation (1). First, Equation (1) includes aggregate energy prices but the specific policies we consider affect electricity and natural gas prices in different ways. Consequently, we distinguish 
between the consumption of electricity and the consumption of fuels, which primarily include natural gas and petroleum products for the manufacturing industries studied here.

Second, Equation (1) includes the assumption that energy prices affect economic activity in proportion to the cost share of energy. Aldy and Pizer (2015) and others in the literature make a similar assumption, but given the available data we can partly relax this assumption. We define eight industry groups based on their energy cost shares and we allow the coefficient on their cost shares to vary across groups. For industries belonging to the same group, energy prices affect economic activity in proportion to the energy cost shares, but we do not assume any proportionality across groups. This approach allows the data to determine whether energy prices have larger effects for high-consuming groups than for other groups, and allows for nonloglinear relationships among energy prices and outcomes.

Third, we account for indirect energy use. In the short run, with the capital stock fixed, plants select inputs of energy, labor, and materials. Linn (2009) shows that energy prices can affect economic activity directly, by raising the energy costs faced by a plant, as well as indirectly, by affecting the prices of materials inputs. Ganapati, Shapiro, and Walker (2017) show that energy prices affect marginal costs and output prices for certain industries, providing further evidence that energy prices can affect a plant indirectly via intermediate materials prices. Consistent with these studies, we assume that the indirect effect depends on the energy intensity of the inputs a plant uses. For example, an increase in crude oil prices causes prices of petroleum products to increase, which affects production costs more for plants that use petroleum products than for those that do not. As described below, we use input-output relationships between industries to compute the average electricity and fuels cost shares of the materials each plant consumes. We interact the electricity and fuels cost share variables with their corresponding prices.

Fourth, we control for the plant's labor costs. We allow the coefficient on labor costs to differ across the energy cost share groups. Further, we recognize that energy prices may be correlated with product demand. Energy price increases often accompany or precede macroeconomic downturns, which would bias estimates of the effects of energy prices on economic activity. We control flexibly for national industry-level demand shocks by including interactions of industryand year-fixed effects. We take two approaches to control for subnational demand shocks. Using 
an approach that builds on Ellison and Glaeser (1999), we control for product demand of an individual plant based on input-output relationships between industries as well as a plant's proximity to demanding industries. In addition, we include interactions of fixed effects for Census region and year to allow for regional demand shocks. These interactions control for regional changes in input costs, regional product demand shocks, as well as international supply and demand shocks that affect each industry proportionately. The next section describes the construction of these variables in detail.

After making these modifications to Equation (1), we arrive at the estimating equation:

$$
\begin{aligned}
\ln \left(y_{i j t}\right)=\beta_{0}+ & \beta_{1}^{E} s_{j}^{E} \ln \left(p_{i j t}^{E}\right)+\beta_{2}^{E} s_{j}^{E} \ln \left(p_{R, i j t}^{E}\right)+\beta_{1}^{F} s_{j}^{F} \ln \left(p_{i j t}^{F}\right)+\beta_{2}^{F} s_{j}^{F} \ln \left(p_{R, i j t}^{F}\right)+\delta_{1}^{E} m_{j}^{E} \ln \left(p_{i j t}^{E}\right) \\
& +\delta_{2}^{E} m_{j}^{E} \ln \left(p_{R, i j t}^{E}\right)+\delta_{1}^{F} m_{j}^{F} \ln \left(p_{i j t}^{F}\right)+\delta_{2}^{F} m_{j}^{F} \ln \left(p_{R, i j t}^{F}\right)+\gamma_{1}^{E} \ln \left(p_{i j t}^{E}\right)+\gamma_{2}^{E} \ln \left(p_{R, i j t}^{E}\right) \\
& +\gamma_{1}^{F} \ln \left(p_{i j t}^{F}\right)+\gamma_{2}^{F} \ln \left(p_{R, i j t}^{F}\right)+\mu_{1} L C O S T_{i j t}+\mu_{2} D G R O W T H_{i j t}+\delta_{r t}+\delta_{j t}+\varepsilon_{i j t}
\end{aligned}
$$

where the dependent variable is employment, output, value added, or gross operating profits by plant $i$ in industry $j$ and year $t$. Equation (2) includes interactions of the log of the plant's electricity price $\left(p_{i j t}^{E}\right)$ with the industry's electricity cost share $\left(s_{j}^{E}\right)$, as well as the interaction of the log of the electricity price of competing plants $\left(p_{R, i j t}^{E}\right)$ with the cost share. The equation includes corresponding terms for fuel prices, where the superscript $F$ indicates a fuels price index rather than electricity $(E)$. The second line in the equation includes the interactions of the energy price variables with the indirect energy use shares $\left(m_{j}^{E}\right.$ and $\left.m_{j}^{F}\right)$. The variables are average electricity or fuels cost shares of the industry's materials. The equation includes the principal effects of electricity and fuels prices, with these effects being absorbed by the corresponding industry-year interactions $\left(\delta_{j t}\right)$. The variables $L C O S T_{i j t}$ and $D G R O W T H_{i j t}$ indicate labor costs and demand growth; $\delta_{r t}$ are region-year interactions; and $\varepsilon_{i j t}$ is an error term. The next subsection describes the definitions of the competing energy prices, as well as the construction of the measures for indirect energy use, labor costs, and demand growth.

We estimate Equation (2) separately for each energy cost share group, omitting group subscripts in the equation to simplify the notation. Because we perform a separate estimation for each group, we allow for cross-group heterogeneity in the effects on economic activity of electricity prices, fuels prices, indirect energy use, labor costs, and demand growth. 
The industry-year interactions play an important role in the identification and interpretation of the coefficients on the variables that include energy prices. These interactions control for the effects of energy prices on the average of the outcome for each industry and year. Consequently, the coefficients are identified by deviations from industry-year means of energy prices interacted with cost shares. For this reason, the coefficients capture precisely the second term in the decomposition introduced in the previous subsection - that is, the deviations from the national averages of the effects of energy prices on a plant's outcomes.

Based on the intuition from Equation (1), within a cost share group, we expect that a plant's electricity and fuels prices negatively affect the outcomes, and that the negative effects are larger in magnitude for plants with higher cost shares - that is, the interaction terms for the plant's energy prices are negative. Likewise, we expect positive coefficients for the interaction terms involving energy prices of competing plants. We expect the signs on the indirect energy use interactions to be the same as the signs of the corresponding direct energy use interactions.

\subsection{Estimating National Average Effects}

Equation (2) identifies a plant's deviations from national industry average effects of energy prices. To estimate the total effect of a carbon price, we therefore need to estimate the effects of energy prices on national averages of the four outcomes. To accomplish this, we take an approach similar to that of Aldy and Pizer (2015) and estimate an industry-level regression

$$
\ln \left(y_{j t}\right)=\theta_{0}+\theta_{1}^{E} c_{j}^{E} \ln \left(p_{t}^{E}\right)+\theta_{1}^{F} c_{j}^{F} \ln \left(p_{t}^{F}\right)+\rho_{1} L \operatorname{COST}_{j t}+\rho_{2} \text { DGROWTH }_{j t}+\tau_{t}+\tau_{j}+\varepsilon_{j t}
$$

where the dependent variable is employment, output, value added, or gross operating profits by industry $j$ and year $t$. The equation includes the interaction of the industry's electricity or fuels cost share with the log of the average price of electricity or fuels in year $t$. Because there is less price variation in the aggregate than in the plant-level data, we add the direct and indirect cost shares in Equation (2) to create a combined cost share, $c$, in Equation (3). The variables for labor costs and demand growth are defined similarly to Equation (2), except that they are aggregated across plants. The equation includes year and industry fixed effects, and an error term. 
The coefficients on the cost share-energy price interactions are the key coefficients of interest. They are identified by time series variation in energy prices interacting with crossindustry variation in cost shares. For example, if the price of electricity increases between one year and the next, the interaction coefficient is identified by cross-industry variation in the response of the dependent variable to the price increase. One expects an electricity price increase to have a larger negative effect for industries that consume more electricity than others (either directly or indirectly via intermediate materials), in which case the interaction coefficient is negative. Note that the equation omits the main effects of the cost shares and energy prices because they are absorbed by the industry and year fixed effects. The year fixed effects control for average energy prices in other countries and any other global demand or supply shocks that affect all industries proportionately. Therefore, the energy price coefficient captures the effects of domestic energy prices, holding international prices fixed. This is an important aspect of the estimation because the simulations implicitly hold international prices fixed. The labor cost and demand growth variables account for supply and demand shocks that vary across industries.

Although Equation (3) is broadly similar to Aldy and Pizer (2015), there are a few important differences. First, and most importantly, we estimate separate effects for electricity and fuels prices. This is consistent with Equation (2), and enables us to simulate carbon prices that affect electricity prices only, as well as carbon prices that affect both electricity and fuels prices. Second, we include only industry and year fixed effects rather than interactions of year fixed effects with aggregated industry fixed effects. Including only the year fixed effects rather than additional controls is for consistency with the simulations discussed below. Third, we use aggregate energy prices rather than industry-specific energy prices to reduce concerns about endogeneity. Fourth, we account for both direct and indirect energy use, which is consistent with the empirical analysis cited above as well as the plant-level estimation in Equation (2), and allows for the possibility of indirect effects of energy prices acting through intermediate materials prices. Finally, we omit controls for oil prices, physical capital, and human capital. These choices are motivated primarily by parsimony to focus on the key coefficients of interest. In practice, these differences do not appear to substantially affect the results; we obtain similar estimates to those reported in Section 4 if we use a specification more similar to Aldy and Pizer (2015). 


\section{Data and Summary Statistics}

Our analysis is based on confidential plant-level data collected by the Census Bureau in the Census of Manufactures (CMF) and the Annual Survey of Manufactures (ASM), which provide data on output, revenue, employment, and expenditures. The CMF is conducted every five years and includes data from all manufacturing plants; we use all years of the CMF from 1982-2007. The ASM samples small plants and includes all large plants; we use the ASM data from 19832011. The ASM and CMF records are linked together over time in the Longitudinal Business Database, as described in Jarmin and Miranda (2002). Our final dataset includes about 2.5 million plant-year observations, covering all manufacturing industries except those that shifted in or out of the manufacturing sector during the 1997 switch from the Standard Industry Classification (SIC) to the North American Industry Classification System (NAICS) industry definitions.

Four measures of economic activity in the ASM/CMF data provide the dependent variables for our analysis: employment, output, value added, and profits. Employment is measured as the plant's total employment including both production and nonproduction workers. Output is measured as the plant's total value of shipments. Value added is measured in the ASM/CMF by taking the value of shipments and subtracting the combined costs of materials, supplies, containers, fuels, purchased electricity, and contract work, adjusting for inventory changes. ${ }^{7}$ Profit is measured by gross operating profits, obtained by subtracting labor costs from value added. Output, value added, and profits are all deflated by the industry's price deflator for shipments from the NBER-CES Manufacturing Industry Database. ${ }^{8}$

Our key explanatory variables are related to energy costs. The ASM/CMF data provide annual plant-level expenditures separately for electricity and fuels and also provide the quantity of electricity purchased. We calculate average (rather than marginal) plant-level electricity prices as the ratio of electricity expenditure to the quantity of purchased electricity. Using the 1992 CMF, we calculate the average share of electricity or fuels in the value of shipments by industry. Under the standard assumption that plants earn zero economic profits in the long run, these shares equal the corresponding cost shares.

${ }^{7}$ https://www.census.gov/glossary/\#term Valueadded.

${ }^{8}$ https://www.nber.org/data/nberces.html. 
Because the ASM/CMF data do not include quantities of purchased fuels throughout the sample, we use state-level industrial prices for five fuels (coal, natural gas, distillate fuel oil, residual fuel oil, and liquefied natural gas) from the US Energy Information Administration. The computed fuels price varies by industry, state, and year and equals the weighted average price across the five fuels using expenditure shares as weights from the 1981 ASM.

We use geocoded Census data from the Longitudinal Business Database to approximate cross-state competition among plants. First, we randomly select 10,000 ASM/CMF plant observations from each state. If at least 1,000 of the businesses in one state are located within 500 miles of 1,000 businesses in another state, those two states are deemed to be neighbors. We calculate neighbor electricity and fuels prices for each plant in our sample as the average of the electricity and fuels prices across all plants in the same industry in neighboring states. These neighbor prices vary by industry, state, and year, and they account for geographic concentration of plants within a state.

The labor cost index is computed from the labor cost for plants in the same industry and state, as well as plants in the same industry in neighboring states. The index is the total payroll for all such plants divided by their total employment, using the 500-mile definition to define the set of neighboring plants and excluding the plant's own payroll and employment.

The demand growth index varies by plant and year and is based on downstream economic activity and shipping patterns. First, input-output (IO) tables from the US Bureau of Economic Analysis (BEA) identify for every "making" industry how much of its output is purchased by each "using" industry. We use both the $1992^{9}$ (SIC-based) and $2007^{10}$ (NAICS-based) IO tables, and use concordances between the BEA industry codes and the SIC/NAICS industry codes to link the IO tables to each of our plants in each year, identifying which other industries (both manufacturing and nonmanufacturing industries, including final demand) purchase that plant's products. Second, the 2002 Commodity Flow Survey (CFS) identifies the distances traveled by shipments from plants in each industry, reported by three-digit NAICS industry of the shipped products. ${ }^{11}$ For each three-digit NAICS industry, we compute the share of shipments traveling less than 250 miles, the share of shipments traveling between 250 and 1,000 miles, and the share of shipments traveling more than 1,000 miles. Third, annual state-level industry output data from

\footnotetext{
${ }^{9}$ http://www.bea.gov/industry/io benchmark.htm.

${ }^{10}$ http://www.bea.gov/industry/io annual.htm.

${ }^{11}$ http://www.rita.dot.gov/bts/sites/rita.dot.gov.bts/files/publications/commodity_flow_survey/index.html.
} 
BEA identifies the activity level of different "using" industries around the country, with final demand proxied by personal income in the state. ${ }^{12}$

For each plant in our dataset and for each industry that uses the products of that plant, we calculate the amount of that industry's production that is located in states within 250 miles of the plant (including the plant's own state), between 250 and 1,000 miles from the plant, or more than 1,000 miles from the plant. We then use the IO data to predict the demand for the plant's products, aggregated over all these "using" industries, at each of the three distances. We calculate the annual growth rate in product demand at each distance and weight those three growth rates using the CFS weights for the share of the plant's shipments expected to travel those distances, yielding a weighted projected demand growth. Finally, we transform these growth rates into an index number by assigning them all a value of 150 in $1987 .{ }^{13}$

We allow for differences among groups of industries in our estimation models, based on the energy intensity as measured by the industry's total expenditure on electricity and fuels divided by its total shipments. We split the industries into 8 separate groups, with greater detail provided among industries with higher energy intensity. Group 1 includes half of the 6-digit NAICS industries, with each of Groups 2-4 including 10 percent each and each of Groups 5-8 including 5 percent. Table 1 shows some key information for each group, such as the share of the sample and the energy cost shares. Plants in more energy intensive (higher-numbered) groups tend to have higher expenditures on both electricity and fuels but otherwise don't differ much in their average employment, shipments, value-added, or operating profits.

We define high-energy industries as those belonging to Groups 5-8, which collectively include the top quintile of energy-intensive industries. Figure 1 shows the variation over our time period in average energy prices and cost shares as well as output and employment for the entire manufacturing sector and for high-energy manufacturing industries. The cost share of highenergy industries declined by half over the period (from about 6 to 3 percent), and energy cost shares declined by about one-third in the manufacturing sector as a whole (from about 3 to 2 percent). In contrast, energy prices followed similar trends for high-energy industries and all industries. Output growth was noticeably slower for high-energy industries as compared to others, while the decline in employment over the period was similar in both groups. Figure 2 shows geographic variation of electricity and fuels prices. Among RGGI or potential RGGI states, New Hampshire, Connecticut, and Massachusetts have the highest electricity prices; Vermont and New Jersey have the highest fuels prices.

\footnotetext{
${ }^{12} \mathrm{http}: / / \mathrm{www}$. bea.gov/regional/index.htm.

${ }^{13}$ The starting value of 150 in 1987 was chosen so that the demand index numbers would remain positive throughout the sample for all industries.
} 


\section{Estimation Results}

\subsection{Deviations from National Average Effects}

Equation (2) includes multiple coefficients on energy prices and energy price interaction terms. There are separate terms for electricity and fuels prices; interactions of those prices with corresponding cost shares; prices for competing plants and interaction terms; as well as for direct and indirect energy use; and a separate set of coefficients for each of the 8 groups, for a total of 96 energy-related coefficients. Because of this large number of coefficients, we focus on the overall elasticities with respect to energy prices, which include both the direct effect of energy purchased by the plant and the indirect effect via the energy-intensity of its purchased materials. ${ }^{14}$

Figure 3 plots the elasticities for employment and output by group for electricity prices, and Figure 4 provides the analogous information for fuels prices. The figures illustrate separately the elasticities with respect to the plant's own energy prices as well as the energy prices of competing plants in neighboring states. The figures show the elasticities and confidence intervals for each group. (The underlying regressions were estimated with clustering by industry-year.)

The own electricity price elasticities in Figure 3 (panels A and B) are typically negative and increase in magnitude, moving from the low cost-share groups to the high cost-share groups. The increase is not perfectly monotonic, and there are deviations for Group 6 (employment) and Group 7 (output). The mean employment elasticities range from -0.07 to -0.90 across the 8 groups, while the output elasticities range from -0.07 to -1.19 , with all of them statistically significant at the 5-percent level. The fact that there are a few positive elasticities is perhaps not surprising, given the flexible functional form of Equation (2) and the large number of estimated coefficients (that is, one would expect that by chance there would be a few positive and statistically significant coefficients).

The own fuels price elasticities in Figure 4 (panels A and B) are also typically negative ( 3 of 16 are positive but only one of those is significant, while 12 of the 13 negative elasticities are significant), but they are smaller and less precisely estimated than the electricity elasticities. The

\footnotetext{
${ }^{14}$ The full set of coefficients are available from the authors.
} 
relationships between the cost shares and the elasticities of the groups are weaker than for electricity. The significant negative elasticities range from -0.08 to -0.29 for employment and from -0.10 to -0.32 for output across the 8 groups.

Overall, for most industry groups the own-electricity elasticities are negative and the magnitudes increase with the cost share. The neighbor elasticities tend to be positive but there is not a correlation between the magnitude of the elasticities and the cost share. Own-fuel elasticities tend to be negative and neighbor-fuel elasticities tend to be positive, although there are a few exceptions to these patterns.

These elasticities are similar to those found in Gray, Linn, and Morgenstern (2016), in which we applied a similar model to plant-level data for 49 energy-intensive, trade-exposed industries and found average elasticities with respect to electricity prices of -0.6 for employment and -0.8 for output. Two other papers in the literature estimate own-price elasticities but not neighbor elasticities. Aldy and Pizer (2015) find a somewhat lower elasticity of output with respect to energy prices of -0.4, using national-level industry data from 1986-1994. Kahn and Mansur (2013) use County Business Patterns data and report estimates similar to ours, finding an elasticity of output with respect to electricity prices ranging from -0.2 for their average industry to -2.2 for their most electricity-intensive industry (primary metals).

The elasticities for competitors' energy prices, seen in panels C and D of Figures 3 and 4, are typically positive for both electricity and fuels. As with the own-energy price elasticities, the elasticities with respect to neighbors' electricity prices are larger in magnitude and more precisely estimated than those for fuels. This difference between electricity and fuels elasticities is similar to that reported in Gray, Linn, and Morgenstern (2016) for electricity and natural gas, and likely reflects the lesser variation across states in prices for fuels. Across the 8 groups, the majority of the elasticities with respect to neighbors' energy prices have the expected positive sign and are statistically different from zero.

\subsection{National Average Effects}

Table 2 reports the estimates of Equation (3), for which we regress the variable indicated in the column heading on electricity and fuels prices interacted with cost shares. Recall that the energy price variables include both the direct and indirect effects. For each dependent variable, 
the coefficient estimates are negative, which is as expected and consistent with the literature. Unfortunately, we do not have sufficient variation to precisely estimate the electricity coefficients. The fuel coefficients are estimated at the 5-percent confidence level or better.

\section{State Carbon Prices and Competitiveness}

\subsection{Main Scenarios}

The objective of the simulations is to illustrate the effects of state carbon pricing on competitiveness. In this subsection we define the two main scenarios that we analyze in comparison to a no-policy baseline scenario.

The baseline scenario uses the observed energy prices and other independent variables across the entire estimation sample. We use Equation (3) to predict national average outcomes for each industry and Equation (2) to predict deviations from the national averages. By construction, the predicted values are equal to the observed sample means.

To compare with the baseline, in the first policy scenario we add a carbon price of $\$ 10$ per ton of $\mathrm{CO}_{2}$ that raises electricity prices in the RGGI region, which includes Connecticut, Delaware, Maine, Maryland, Massachusetts, New Hampshire, New York, Rhode Island, and Vermont. For simplicity, we assume that the carbon price raises electricity prices in proportion to the emissions rate of a natural gas-fired unit. Consequently, electricity prices increase by 0.6 cents per kilowatt hour in the RGGI states. ${ }^{15}$ We also assume that the carbon price does not affect electricity prices in other states or fuels prices in any states. Consequently, for plants in RGGI, their own electricity prices rise and the electricity prices of competing plants are unchanged. For plants close to RGGI, their own electricity prices are unchanged and the electricity prices of competing plants rise. ${ }^{16}$

\footnotetext{
15 The effect of the carbon price on electricity prices is broadly consistent with estimates reported in Linn and Muehlenbachs (2018), who estimate the effect of fuels prices on wholesale electricity prices using data from the 2000s.

${ }^{16}$ In principle, a carbon price in RGGI could affect electricity prices outside the region. The carbon price raises the cost of producing electricity in RGGI, which could increase generation from outside the region, causing marginal costs and electricity prices to increase. Shawhan et al. (2014) suggest that for a carbon price of $\$ 10$ per ton of $\mathrm{CO}_{2}$, this effect would be small compared to the increase in electricity prices in the RGGI region. For simplicity, the simulations do not include this effect.
} 
Equation (2) and these counterfactual plant-level electricity prices are used to predict deviations from national averages of employment, output, and profits. Then, we use Equation (3) to predict national average changes for each industry. The price increases for RGGI and the share of RGGI plants in national employment are used to compute the change in national average electricity prices. Because RGGI plants account for about 10 percent of national employment on average across all industries, national average electricity prices increase by about 2 percent for the average industry. We combine the results of Equations (2) and (3) for each plant in the dataset, and then compute percent changes in the outcomes for each plant, relative to the no-policy baseline.

Based on the estimation results reported in the previous section, we expect the RGGI carbon price to reduce employment, output, and profits in RGGI states and increase those outcomes in surrounding states. The total effect across the entire country should be negative, because national average electricity prices increase. Because the plant-level elasticities (in Equation 2) tend to be larger in magnitude than the industry-level elasticities (in Equation 3), we expect the carbon price to induce shifts of employment, output, and profits to unregulated states.

The second carbon price scenario expands the RGGI carbon price to New Jersey and Pennsylvania. The plant-level outcomes are computed similarly to the first scenario. Relative to the no-policy scenario, we expect lower employment, output, and profits in the expanded RGGI region. Relative to the original RGGI scenario, we expect less of a reduction in employment, output, and profits since the average electricity prices of competing plants increase by less in the expanded RGGI scenario than in the original RGGI scenario.

\subsection{Main Results}

The main results are presented in a series of maps that illustrate the changes relative to the baseline scenario, showing state-specific effects on employment and output for the eastern half of the country, which includes all states that are neighbors of RGGI. In addition to the maps, Table 3 shows the average effects of each scenario for various groups of states, including the effects on profits as well as employment and output.

The results of the simulations generally follow the expected pattern, with reductions in employment, output, and profits in the RGGI states and increases in neighboring states. The 
effects tend to be larger for RGGI states such as New York, Maryland, and Delaware that are located closer to non-RGGI states. The output effects tend to be larger than the employment effects, which is consistent with the elasticities seen in Figures 3 and 4 . In Table 3 for the first scenario, the RGGI carbon price reduces average manufacturing employment in those states by 2.7 percent, and raises average employment in New Jersey and Pennsylvania by 0.8 percent (the increases are smaller in other eastern states). However, the maps show some variation in effects that are uncorrelated with the distance from RGGI states. For example, Figure 5 shows larger output changes for Kentucky and Tennessee than for some other states that are closer to RGGI. These variations could arise because of the specific mix of industries operating in RGGI and non-RGGI states, since relative energy prices only matter if there are competing plants in neighboring states to take advantage of the energy price differential. Thus, in Figure 5C we see larger output effects for Kentucky and Tennessee than for some other states that are closer to more RGGI states.

The effects of the carbon price on the high-energy industries are generally larger than for the average industry, as expected. The average employment in those industries falls by 7.1 percent in the RGGI states and output falls by 10.5 percent. The increases in employment and output in neighboring non-RGGI states are also larger than for the average industry, although still only about 0.5 percent. These larger effects make it easier to identify differences across particular states, including the variation across states within the regions shown in Table 3, which again shows Kentucky and Tennessee with larger output effects than those found for some other states closer to RGGI.

The results for the second scenario, where Pennsylvania and New Jersey join RGGI and adopt carbon prices, are as expected. The results are shown in Table 3 and Figure 6. Because of their location, those states now form a buffer between some of the original RGGI states and the neighboring non-RGGI states, and the effects on their employment and output are somewhat smaller on average than they were in the first scenario. The average across industries is a decline of 2.2 percent in employment and 3.4 percent in output, with similar reductions for the highenergy industries. The average declines in employment and output for Pennsylvania and New Jersey are larger than those for the original states, with a 3.3 percent decline in average employment and a 4.9 percent decline in average output across all industries. The estimated 
effects on high-energy industries are also larger than those in the original RGGI states. The increases in the non-RGGI states are also larger than they were in the first scenario, reflecting the greater number of neighboring states with carbon prices. Table 3 also shows the predicted effect on operating profits, which is slightly larger than the effects on output, ranging up to a decrease of 11.2 percent for the high-energy industries in RGGI states.

\subsection{Other Results}

In this subsection we discuss the results of two variations in our scenarios. First, we redefine the RGGI and expanded RGGI scenarios so that the carbon price affects both electricity and fuels prices, rather than just electricity prices. This scenario corresponds to a situation in which the RGGI states decide to expand their programs to include fuels directly combusted (a California-style approach). The effects of this scenario are shown in Table 3 and Figure 7. Compared to the electricity-only scenario, the differences are due largely to the mix of specific industries operating in each state. Arguably, we might have expected to see larger effects, given the wider range of energy sources affected by the carbon price-but the average reductions in employment and output in the RGGI states are not much different from those in the first scenario. This may reflect the presence of a few unexpected signs for the own and neighbors' employment elasticities with respect to fuels prices. Figures 7A and 7B show employment reductions that are more concentrated in New York and Maryland than in the first scenario (Figure 4), and employment gains that are more concentrated in Pennsylvania and New Jersey.

Second, we set the carbon price to equal \$25 per ton rather than \$10 per ton in the RGGI electricity scenario, representing a tightening of the RGGI emissions caps. Figures 7C and 7D show the effect on employment for this scenario. The patterns across specific states are similar to those seen in the second scenario, but it's important to note that the scale of the map's colors needed to expand to reflect the larger effects seen here, with increases going up to 4 percent rather than 2 percent and reductions going down to 25 percent rather than 15 percent.

\section{Conclusions}

A substantial literature has analyzed empirically and theoretically the potential for international emissions leakage, in which a country or set of countries impose a carbon price that raises emissions in other countries. Accompanying the emissions leakage would be 
corresponding shifts of employment, output, and profits to firms located in unregulated countries, representing the adverse competitiveness effects of the carbon price.

In the United States, certain states have adopted or are considering adopting a carbon price. The high degree of trade of manufactured goods across state lines raises the possibility of a substantial amount of leakage of economic activity across states. In the state-level policy context, leakage would be concerning not only because it would undermine the climate objectives of a carbon pricing policy but also because it would imply losses of local jobs and production. As policies evolve in this area, it is important to understand the magnitudes of potential leakage under state-level carbon pricing policies.

Clearly, it is not simply a matter of energy or carbon price differences across jurisdictionsthe industry mix in different areas is also a major factor. Carbon pricing by a jurisdiction that has a monopoly or near monopoly on particular production capabilities would likely result in minimal competitiveness effects in that jurisdiction. Thus, to estimate the employment, output, or profit sensitivity of a particular jurisdiction requires consideration of multiple state- and regionspecific factors of the type included in our modeling.

We decompose the effects of a carbon price on three plant-level outcomes (employment, output, and profits) into two effects: the change in the national average level of that outcome for all plants in the corresponding industry, and the individual plant's outcome deviation from the national industry average. The first part is estimated via similar methods as Aldy and Pizer (2015). We use a novel model and unique data to estimate the second part. Specifically, we link a plant's outcome deviations to the energy prices it faces as well as the energy prices of competing plants. This model thereby captures differing effects of the carbon price across plants in the same industry. For plants in the regulated region, the carbon price raises energy prices, making them less competitive, while plants outside the regulated region become more competitive. The model is further distinguished by separating the effects of electricity and fuels, and by allowing for indirect effects of energy prices to affect a plant via the prices of the energy-intensive materials that it uses in its production process.

The model parameters are estimated with confidential plant-level data from the Census Bureau from 1982-2011. As expected, higher energy prices at a plant typically reduce its 
employment, output, and profits, with the magnitude of the effects generally increasing with energy intensity. Higher energy prices at competing plants tend to increase a plant's employment, output, and profits.

We then use the estimated parameters from the model to simulate the effects of regional carbon prices. We focus on the RGGI program, which prices carbon emissions from the electricity sector in the Northeast. A carbon price of $\$ 10$ per ton reduces employment by 2.7 percent in the RGGI region, with comparable changes in output and profits. The same carbon price raises those outcomes in the surrounding states, with a 0.8 percent increase in employment. The national-level outcomes are relatively small, with employment declining by 0.1 percent, confirming that a substantial amount of the shift of output, employment, and profits flowing out of RGGI leaks into surrounding states rather than to other countries. We also show that expanding RGGI to include New Jersey and Pennsylvania would reduce the adverse competitiveness effects within the original RGGI region.

These results imply that state policymakers can reduce the degree of leakage - and the associated environmental and economic costs - by expanding their programs to include other states. The benefits of linking programs across states can be substantial, due to the fact that states' economies are so intertwined with such a high degree of cross-state trade of manufactured goods.

Finally, we note a few caveats regarding our analysis. First, as with most other studies in the literature, we use industry responses to past changes in energy prices to derive estimates of the effects of future carbon policy. That is, we assume that manufacturing plants would respond similarly to energy price increases induced by a carbon price as they have responded to historical price changes. The high degree of persistence of historical energy prices and carbon prices supports this assumption. Second, our analysis covers the short run, in which capital stocks are fixed and there is no entry and exit of plants. Modeling long-run effects that include capital investment, entry, and exit would be a useful direction for future research.

\section{References}


Adkins, Liwayway, Richard Garbaccio, Mun Ho, Eric Moore, and Richard Morgenstern. 2012. "Carbon Pricing with Output-Based Subsidies: Impact on US Industries over Multiple Time Frames.” Discussion paper 12-27. Washington, DC: Resources for the Future.

Aldy, Joseph E., and William A. Pizer. 2015. "The Competitiveness Impacts of Climate Change Mitigation Policies." Journal of the Association of Environmental and Resource Economists 2(4): 565-595.

Boehringer, Christoph, Carolyn Fischer, and Knut Einar Rosendahl. 2010. "The Global Effects of Subglobal Climate Policies." The B.E. Journal of Economic Analysis and Policy 10(2).

Ellison, G., and E.L. Glaeser. 1999. "The Geographic Concentration of Industry: Does Natural Advantage Explain Agglomeration?" American Economic Review Papers and Proceedings 89: 311-316. https://doi.org/10.1257/aer.89.2.311.

Fabra, N. and M. Reguant. 2014. Pass-Through of Emissions Costs in Electricity Markets. American Economic Review 104: 2872-99.

Fischer, C., and R.D. Morgenstern. 2009. "Designing Provisions to Maintain Competitiveness and Mitigate Emissions Leakage.” Policy brief 09-06. Washington, DC: Brookings Energy Security Initiative.

Fischer, C., and A.K. Fox. 2012. "Comparing Policies to Combat Emissions Leakage: Border Tax Adjustments versus Rebates.” Journal of Environmental Economics and Management 64(2): 199-216 (September).

Fowlie, M., M. Reguant, and S.P. Ryan. 2016. "Market-Based Emissions Regulation and Industry Dynamics.” Journal of Political Economy 124: 249-302.

Ganapati, S., J.S. Shapiro, and R. Walker. 2017. “The Incidence of Carbon Taxes in US Manufacturing: Lessons from Energy Cost Pass-Through.” Discussion paper 2038R. New Haven, CT: Cowles Foundation for Research in Economics, Yale University.

Gray, W., J. Linn, and R. Morgenstern. 2016. "Employment and Output Leakage under California's Cap-and-Trade Program.” Discussion paper 16-17. Washington, DC: Resources for the Future.

Jarmin, R.S., and J. Miranda. 2002. “The Longitudinal Business Database.” Working paper 0217. Washington, DC: Center for Economic Studies, US Census Bureau.

Kahn, M.E., and E.T. Mansur. 2013. "Do Local Energy Prices and Regulation Affect the Geographic Concentration of Employment?” Journal of Public Economics 101: 105-114.

Linn, J. 2008. "Energy Prices and the Adoption of Energy-Saving Technology." The Economic Journal 118: 1986-2012. 
Linn, J. 2009. "Why Do Oil Shocks Matter? The Role of Inter-Industry Linkages.” Economic Inquiry 47: 549-567.

Linn, J., and L. Muehlenbachs. 2018. "The Heterogeneous Impacts of Low Natural Gas Prices on Consumers and the Environment." Journal of Environmental Economics and Management 89: 1-28.

Shawhan, D.L., J.T. Taber, D. Shi, R.D. Zimmerman, J. Yan, C.M. Marguet, Y. Qi, B. Mao, R.E. Schuler, W.D. Schulze, and D. Tylavsky. 2014. "Does a Detailed Model of the Electricity Grid Matter? Estimating the Impacts of the Regional Greenhouse Gas Initiative." Resource and Energy Economics 36: 191-207. 
Table 1. Mean Values by Group

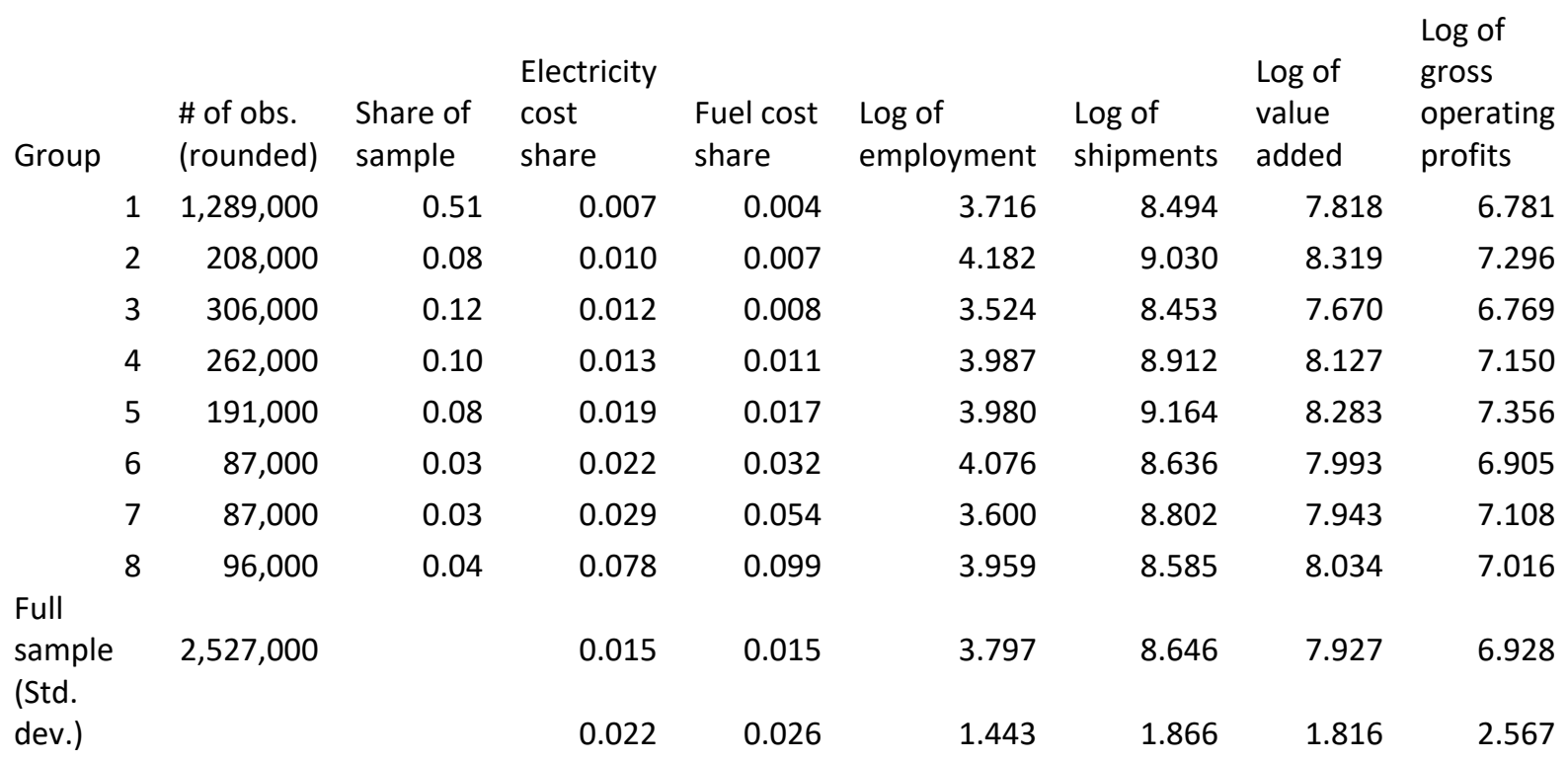

Notes: Groups based on energy cost share (sum of electricity and fuel costs, divided by shipments).

Table 2. Effects of Energy Prices on National Outcomes

Dependent variable is:

\begin{tabular}{|l|c|c|c|c|}
\hline & $\begin{array}{c}\text { Log real value of } \\
\text { shipments }\end{array}$ & $\begin{array}{c}\text { Log real value } \\
\text { added }\end{array}$ & Log employment & Log real profits \\
\hline Log electricity price & -0.01 & -0.17 & -0.04 & -0.14 \\
\hline X cost share & $(0.11)$ & $(0.17)$ & $(0.06)$ & $(0.21)$ \\
\hline Log fuels price & -0.15 & -0.21 & -0.04 & -0.22 \\
\hline X cost share & $(0.07)$ & $(0.09)$ & $(0.02)$ & $(0.11)$ \\
\hline $\begin{array}{l}\text { Number of } \\
\text { observations }\end{array}$ & 13,749 & 13,749 & 13,749 & 13,727 \\
\hline R-squared & 0.92 & 0.92 & 0.92 & 0.89 \\
\hline
\end{tabular}

Notes: The table reports coefficient estimates from Equation (3), with standard errors in parentheses clustered by three-digit NAICS industry and year. See text for details. 
Table 3. Simulation Results for \$10 Carbon Price Applied to RGGI States Including Variation with PA and NJ added to RGGI

\begin{tabular}{|c|c|c|c|c|c|c|c|}
\hline Coverage & Carbon price & Industries & Outcome & RGGI states & $\mathrm{PA}+\mathrm{NJ}$ & $\begin{array}{l}\text { Near } \\
\text { RGGI }\end{array}$ & $\begin{array}{l}\text { Far } \\
\text { RGGI }\end{array}$ \\
\hline RGGI & electricity & all & employ & $-2.71 \%$ & $0.83 \%$ & $0.29 \%$ & $0.12 \%$ \\
\hline RGGI & electricity & all & output & $-3.81 \%$ & $0.67 \%$ & $0.20 \%$ & $0.06 \%$ \\
\hline RGGI & electricity & all & profits & $-4.16 \%$ & $0.31 \%$ & $-0.03 \%$ & $-0.17 \%$ \\
\hline RGGI & electricity & high-energy & employ & $-7.08 \%$ & $1.76 \%$ & $0.61 \%$ & $0.37 \%$ \\
\hline RGGI & electricity & high-energy & output & $-10.51 \%$ & $1.01 \%$ & $0.56 \%$ & $0.42 \%$ \\
\hline RGGI & electricity & high-energy & profits & $-11.24 \%$ & $0.16 \%$ & $0.23 \%$ & $0.16 \%$ \\
\hline RGGI_PA_NJ & electricity & all & employ & $-2.22 \%$ & $-3.32 \%$ & $0.67 \%$ & $0.28 \%$ \\
\hline RGGI_PA_NJ & electricity & all & output & $-3.37 \%$ & $-4.91 \%$ & $0.52 \%$ & $0.18 \%$ \\
\hline RGGI_PA_NJ & electricity & all & profits & $-3.90 \%$ & $-5.09 \%$ & $0.01 \%$ & $-0.27 \%$ \\
\hline RGGI_PA_NJ & electricity & high-energy & employ & $-5.73 \%$ & $-7.82 \%$ & $1.59 \%$ & $0.85 \%$ \\
\hline RGGI_PA_NJ & electricity & high-energy & output & $-9.64 \%$ & $-11.01 \%$ & $1.42 \%$ & $0.94 \%$ \\
\hline RGGI_PA_NJ & electricity & high-energy & profits & $-11.30 \%$ & $-12.17 \%$ & $0.36 \%$ & $0.25 \%$ \\
\hline RGGI & electric+fuels & all & employ & $-2.04 \%$ & $0.77 \%$ & $0.26 \%$ & $0.12 \%$ \\
\hline RGGI & electric+fuels & all & output & $-2.76 \%$ & $0.75 \%$ & $0.31 \%$ & $0.20 \%$ \\
\hline RGGI & electric+fuels & all & profits & $-3.00 \%$ & $0.61 \%$ & $0.18 \%$ & $0.08 \%$ \\
\hline RGGI & electric+fuels & high-energy & employ & $-6.62 \%$ & $1.32 \%$ & $0.61 \%$ & $0.50 \%$ \\
\hline RGGI & electric+fuels & high-energy & output & $-9.59 \%$ & $0.99 \%$ & $0.74 \%$ & $0.73 \%$ \\
\hline RGGI & electric+fuels & high-energy & profits & $-10.42 \%$ & $0.75 \%$ & $0.59 \%$ & $0.65 \%$ \\
\hline RGGI_PA_NJ & electric+fuels & all & employ & $-1.59 \%$ & $-2.57 \%$ & $0.62 \%$ & $0.27 \%$ \\
\hline RGGI_PA_NJ & electric+fuels & all & output & $-2.28 \%$ & $-3.38 \%$ & $0.72 \%$ & $0.42 \%$ \\
\hline RGGI_PA_NJ & electric+fuels & all & profits & $-2.59 \%$ & $-3.53 \%$ & $0.42 \%$ & $0.17 \%$ \\
\hline RGGI_PA_NJ & electric+fuels & high-energy & employ & $-5.62 \%$ & $-7.04 \%$ & $1.44 \%$ & $1.01 \%$ \\
\hline RGGI_PA_NJ & electric+fuels & high-energy & output & $-8.67 \%$ & $-8.77 \%$ & $1.76 \%$ & $1.46 \%$ \\
\hline RGGI_PA_NJ & electric+fuels & high-energy & profits & $-9.91 \%$ & $-10.17 \%$ & $1.23 \%$ & $1.14 \%$ \\
\hline
\end{tabular}

Notes: Simulation results based on coefficients estimated in Equations (2) and (3). The table shows change in average outcome variable for plants located in specified regions, comparing nopolicy ( $\$ 0$ carbon price) with a $\$ 10$ carbon price applied to electricity prices (or both electricity and fuels prices) faced by all plants located in the RGGI region (expanded in some simulations to include Pennsylvania and New Jersey). Results shown separately for all manufacturing industries and those designated as high-energy-cost industries (groups 5-8 in Table 1).

RGGI states: CT, DE, MA, MD, ME, NH, NY, RI, VT.

Near-RGGI states: IN, KY, MI, NC, OH, VA, WV.

Far-RGGI states: AL, FL, GA, IL, MS, SC, TN, WI. 
Figure 1. Comparison of All-Manufacturing and High-Energy-Cost-Industry Trends

Figure 1A. Energy Price and Energy Cost Share

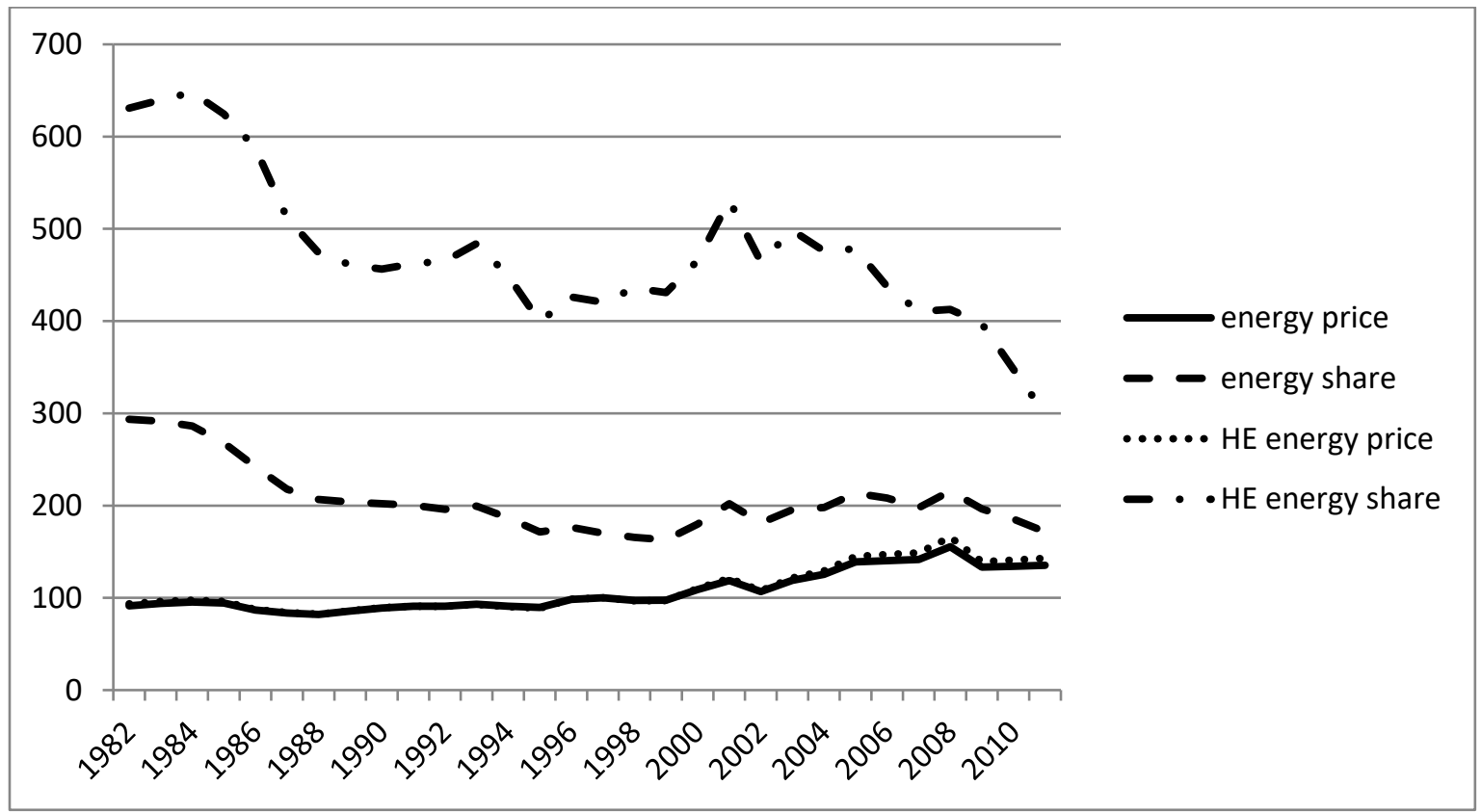

Figure 1B. Employment and Output

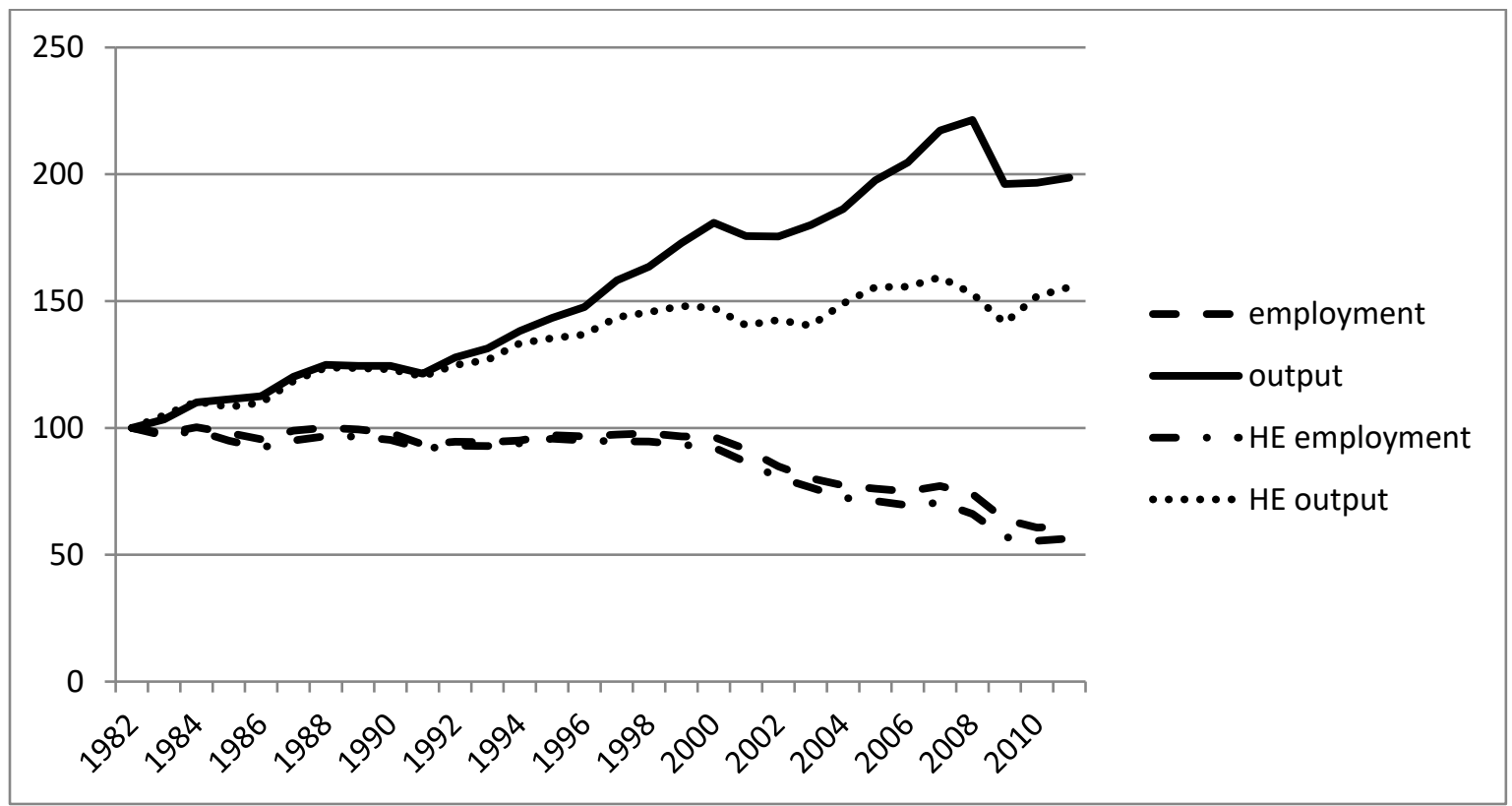

Notes: These figures compare the average values for all manufacturing industries with the average values for the high-energy-cost industries in Groups 5-8. Energy cost shares are scaled, setting $100=$ one percent cost share; all other variables are normalized to 100 in 1982. All numbers based on industry-level data from NBER-CES Manufacturing Industry Database. 
Figure 2. Energy Price Variation Across States in 2011

Figure 2A. 2011 Electricity Prices

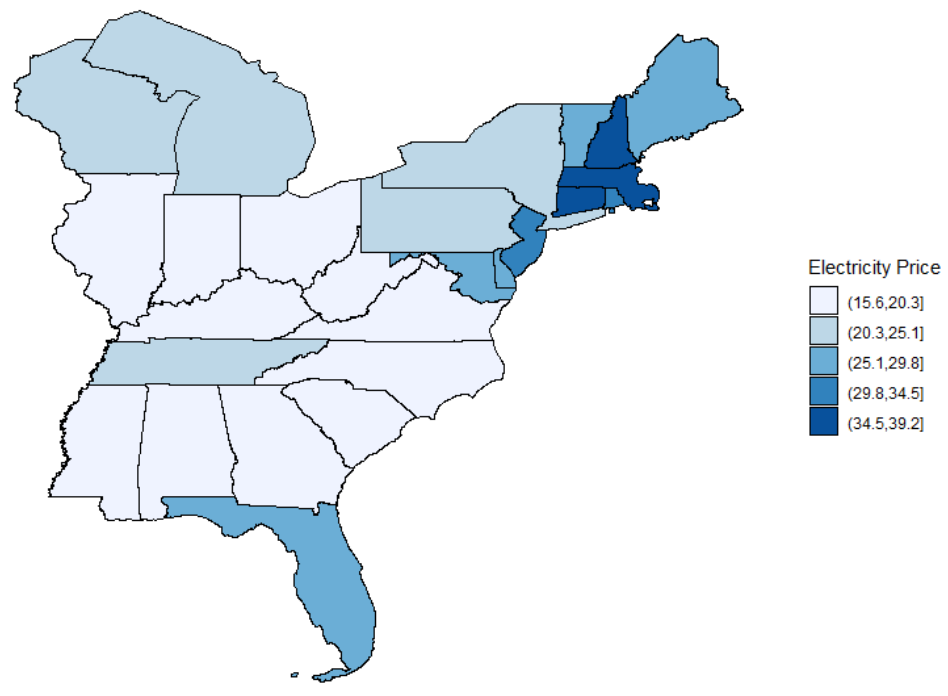

Figure 2B. 2011 Fuels Prices

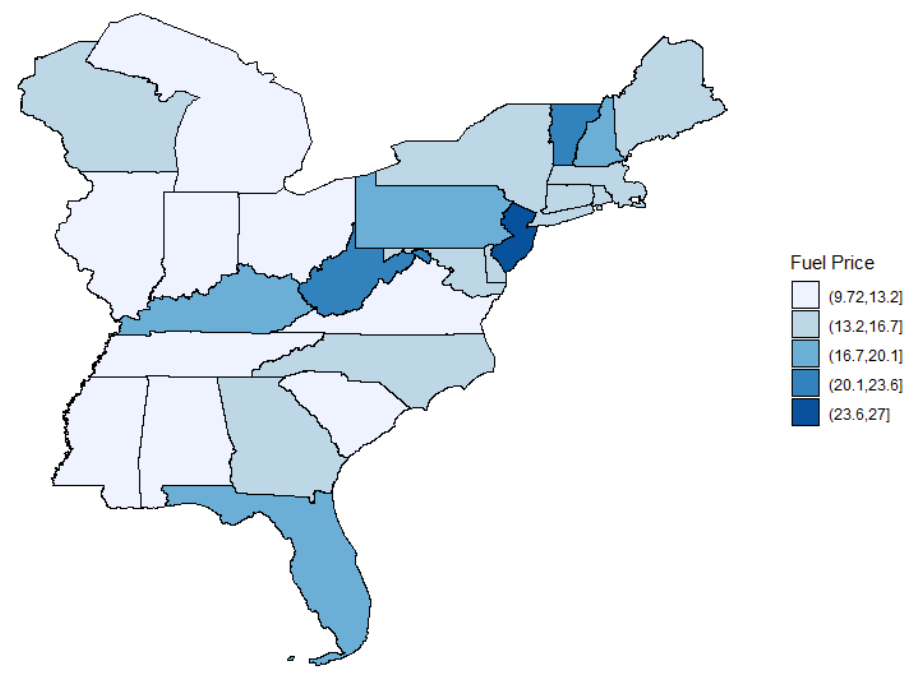

Notes: Both electricity and fuels prices come from the State Energy Data System (SEDS) provided by the US Energy Information Administration (https://www.eia.gov/state/seds/) and are expressed in dollars per million BTU. The electricity price is that paid by industrial consumers in the state. The fuels price includes coal, natural gas, distillate fuel oil, residual fuel oil, and hydrocarbon gas liquids, aggregating the total amount spent on those fuels by industrial consumers in the state and dividing by their total BTU content. 
Figure 3. Employment and Output Elasticities with Respect to Electricity Prices
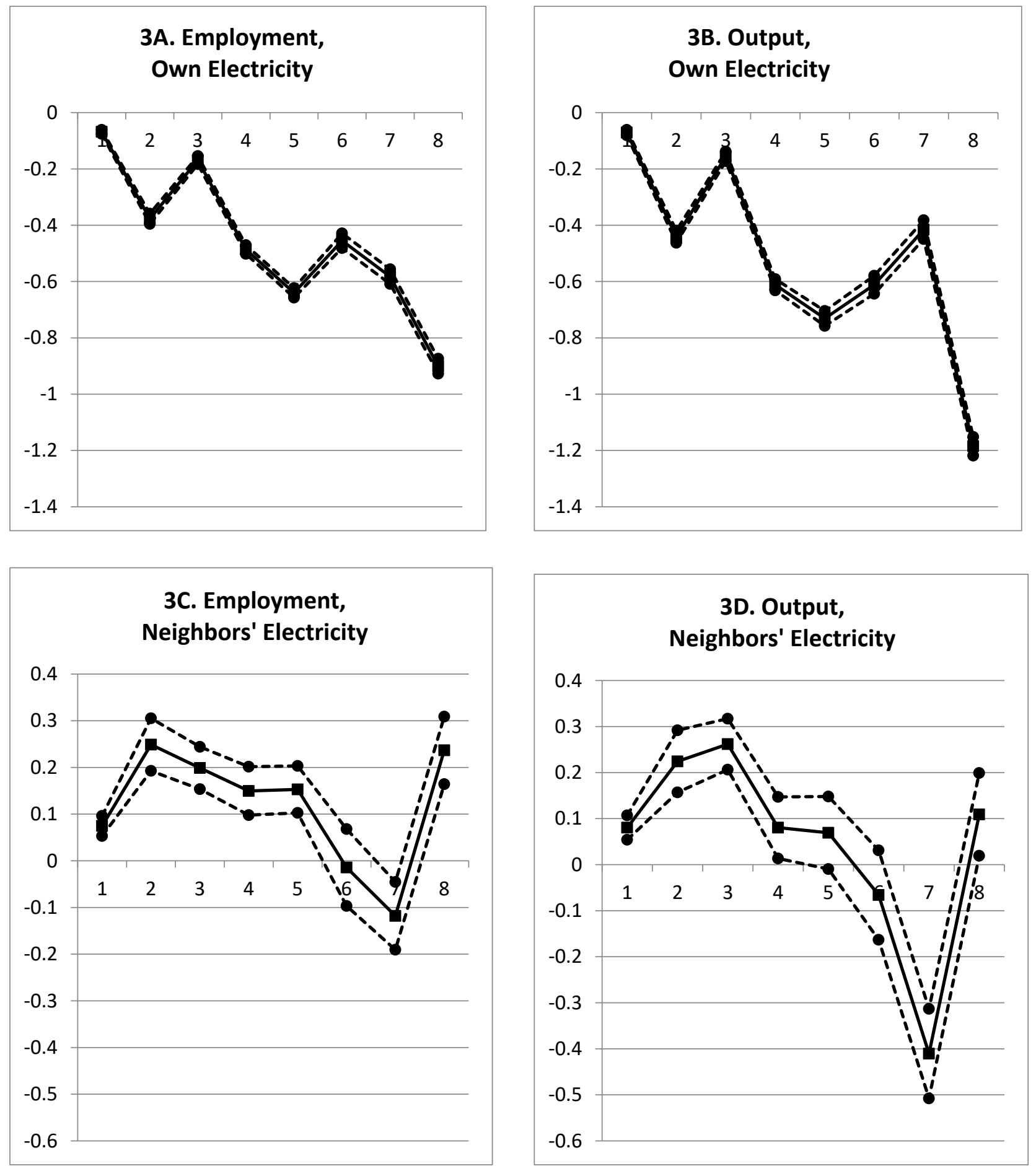

Notes: Estimated elasticity of outcome variables with respect to electricity prices (both own price and neighbor price), based on coefficients from Equation 2, which is estimated separately for 8 industry groups shown in Table 1 (Group 1 is lowest energy cost share; Group 8 is highest). 
Figure 4. Employment and Output Elasticities with Respect to Fuels Prices
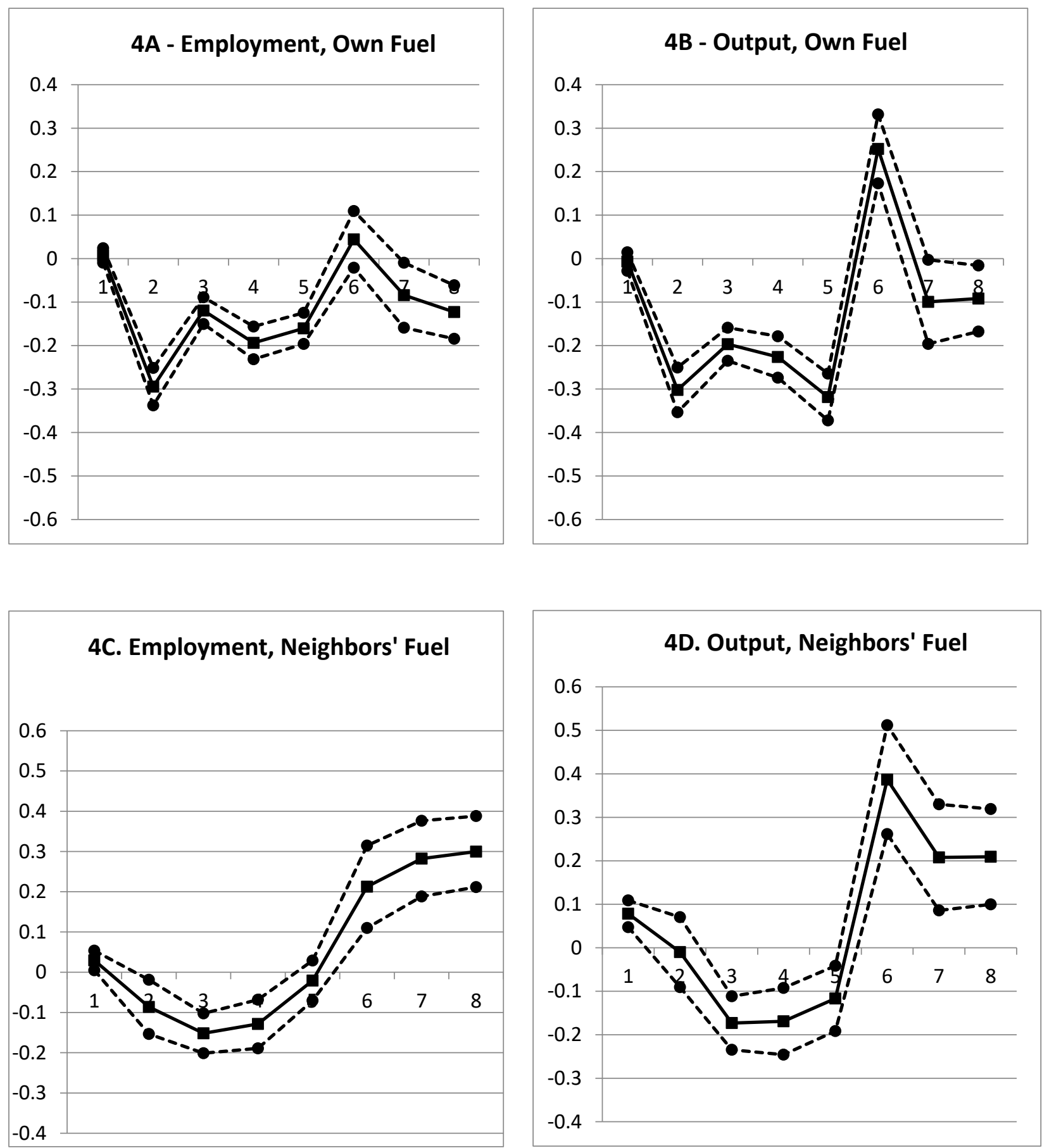

Notes: Estimated elasticity of outcome variables with respect to fuels prices (both own price and neighbor price), based on coefficients from Equation 2, which is estimated separately for 8 industry groups shown in Table 1 (Group 1 is lowest energy cost share; Group 8 is highest). 
Figure 5. Employment and Output Changes with \$10 Carbon Price on Electricity

5A. Employment, All Industries
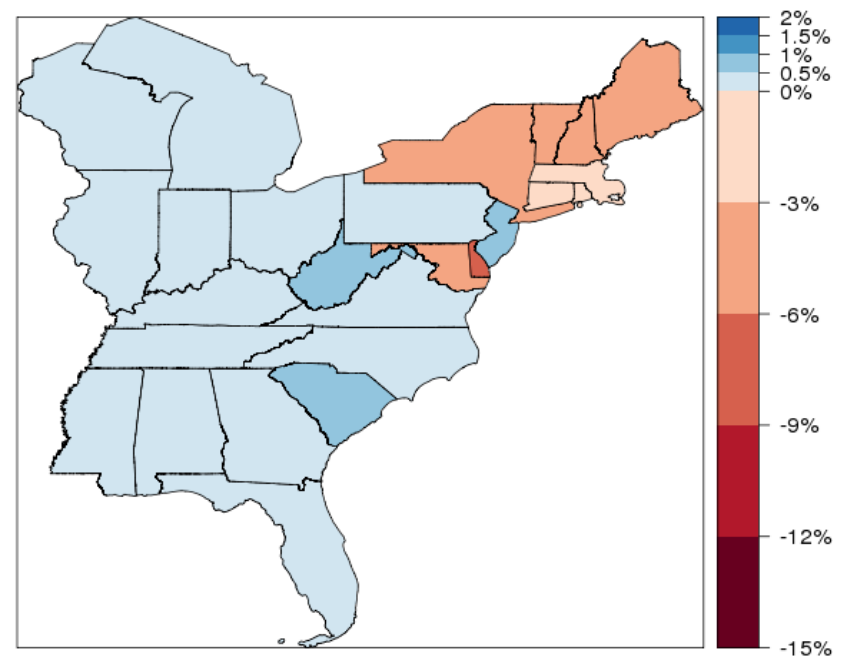

5C. Output, All Industries

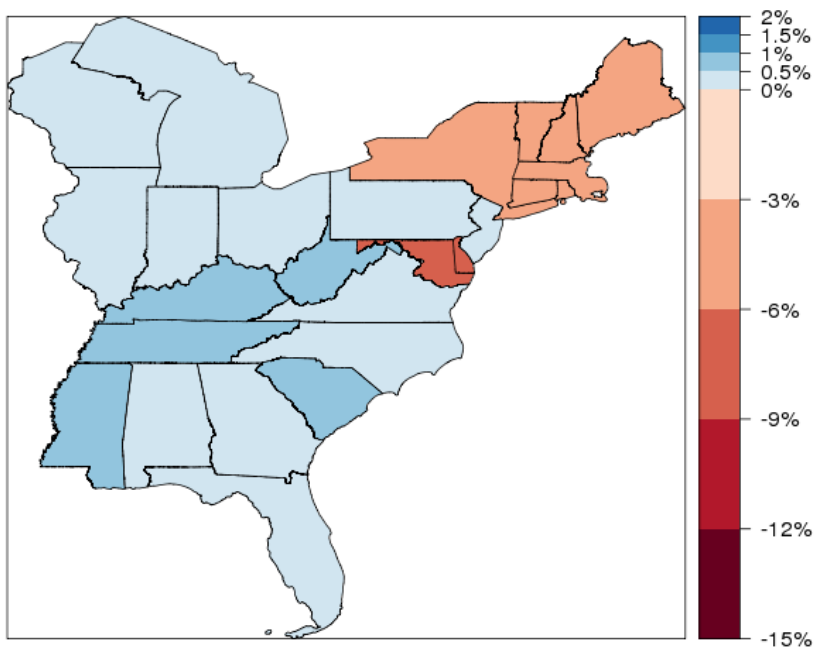

5B. Employment, High-Energy Industries

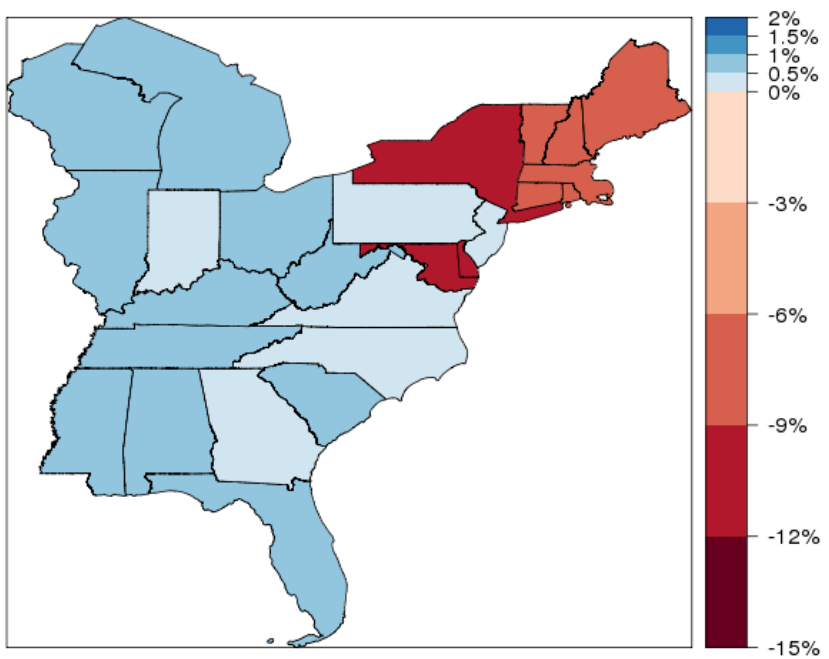

5D. Output, High-Energy Industries

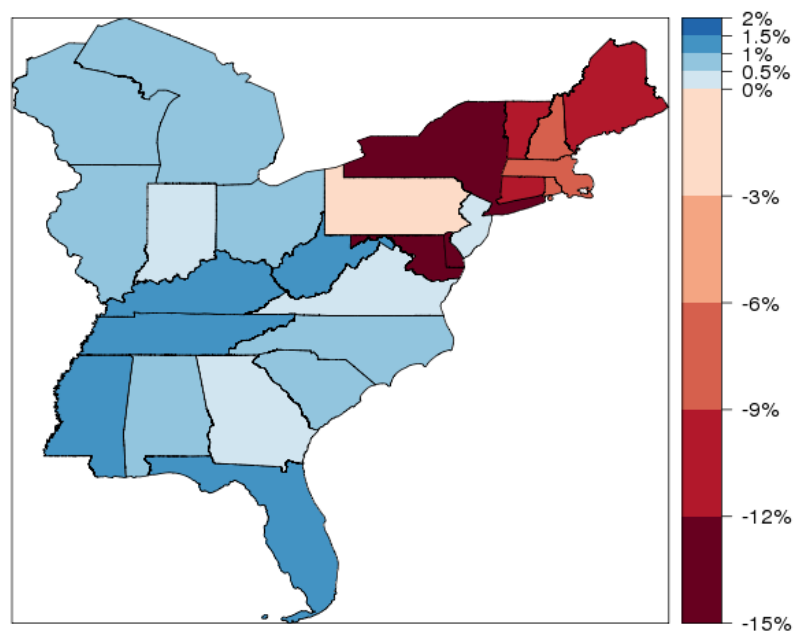

Notes: Simulation results based on coefficients estimated in Equations (2) and (3). The figures show the change in average employment and output for plants located in each state, comparing no-policy (\$0 carbon price) with a \$10 carbon price applied to electricity prices faced by all plants located in the RGGI region. Results shown separately for all manufacturing industries and those designated as high-energy industries (Groups 5-8 in Table 1). 
Figure 6. Employment and Output Effects: Adding PA and NJ to RGGI with \$10 Carbon Price on Electricity

6A. Employment, All Industries

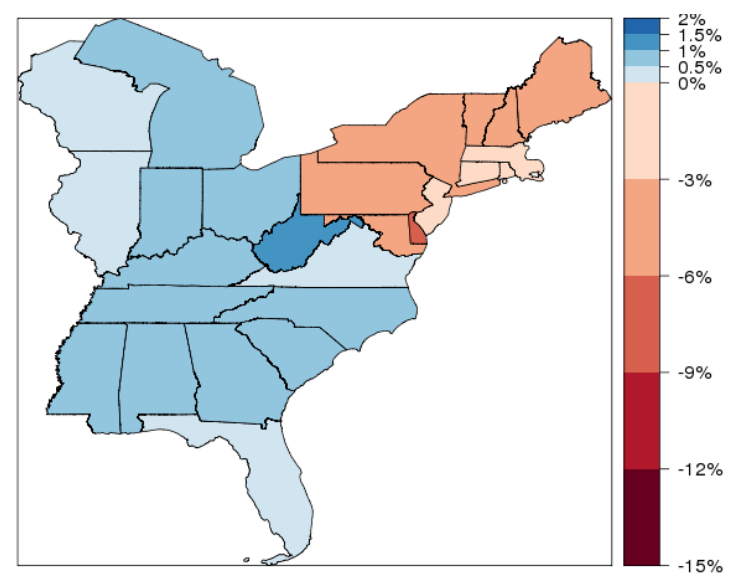

6C. Output, All Industries

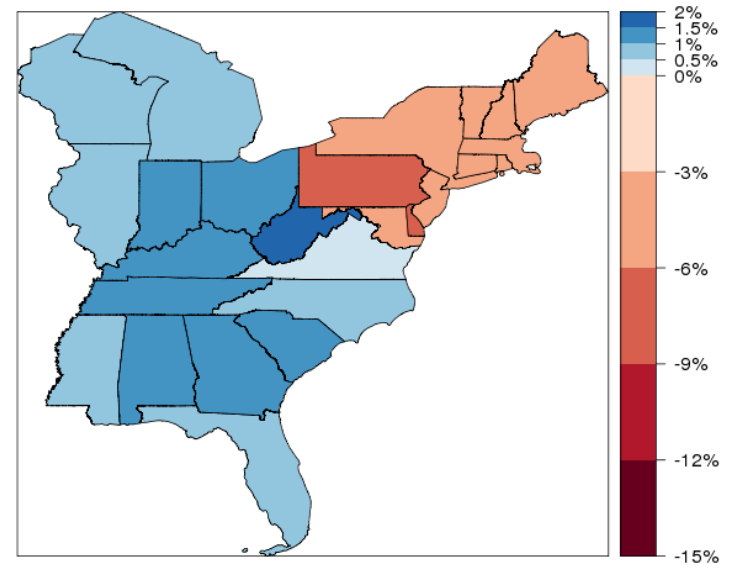

6B. Employment, High-Energy Industries

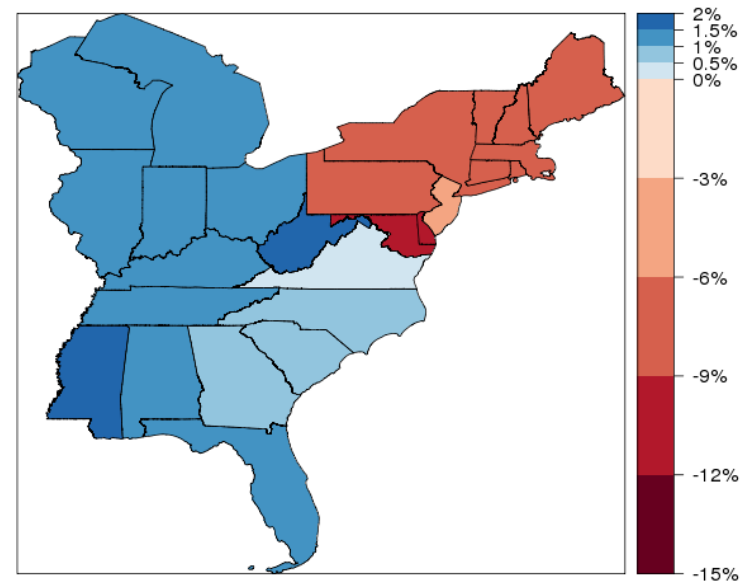

6D. Output, High-Energy Industries

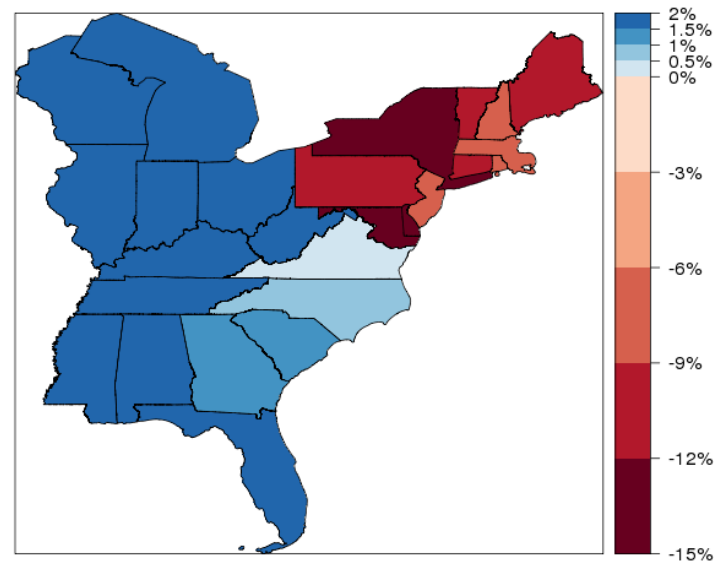

Notes: Simulation results based on coefficients estimated in Equations (2) and (3). The figure shows the change in average employment and output for plants located in each state, comparing no-policy ( $\$ 0$ carbon price) with a $\$ 10$ carbon price applied to electricity prices faced by all plants located in the RGGI region as well as Pennsylvania and New Jersey. Results shown separately for all manufacturing industries and those designated as high-energy industries (Groups 5-8 in Table 1). 
Figure 7. Alternative Scenarios

Employment Changes with $\$ 10$ Carbon Price on Both Electricity and Fuels

7A. Employment, All Industries

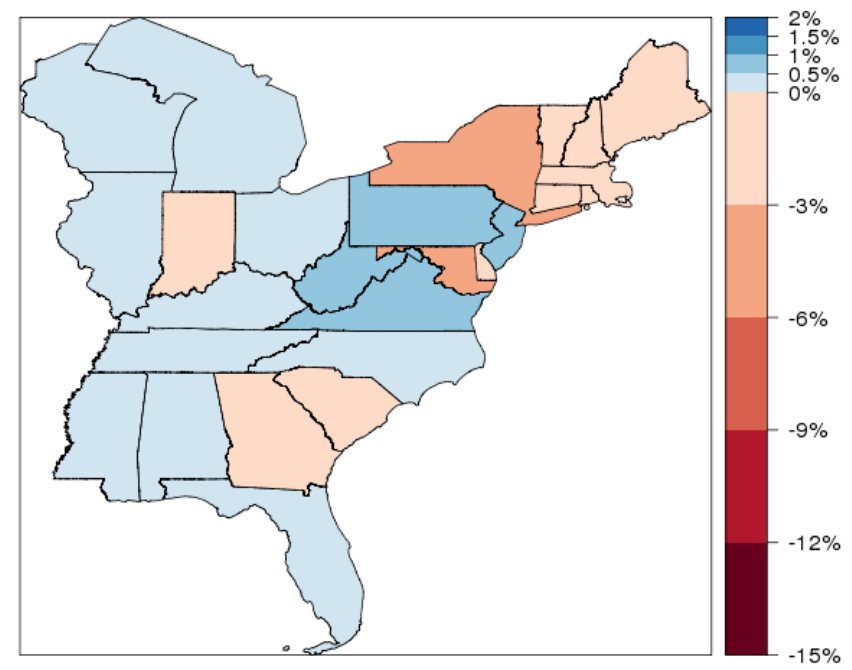

7B. Employment, High-Energy Industries

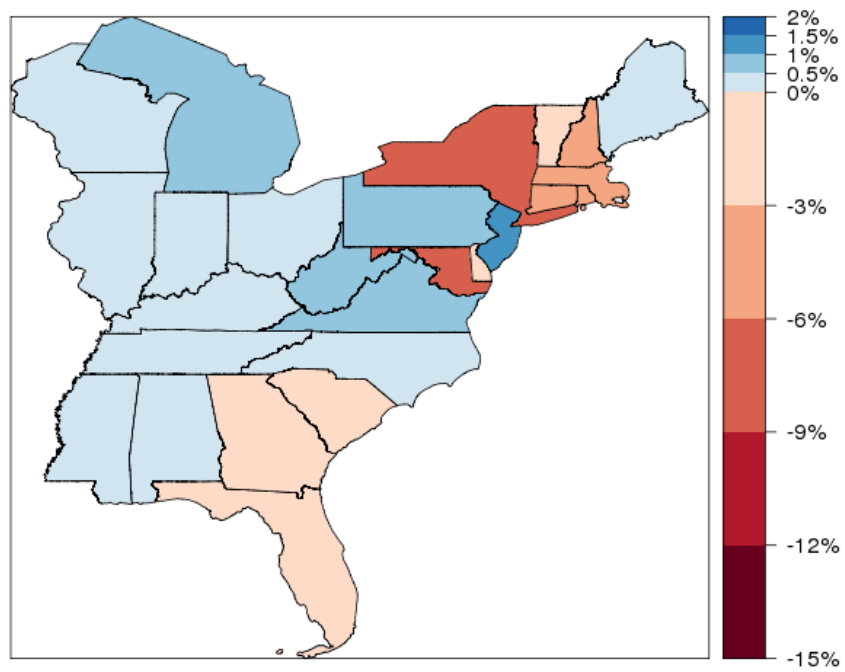

Notes: Change in average employment comparing no-policy ( $\$ 0$ carbon price) with a $\$ 10$ carbon price applied to electricity and fuels prices faced by all plants located in the RGGI region. Results shown separately for all manufacturing and high-energy industries (Groups 5-8 in Table $1)$.

Employment Changes: Adding PA and NJ to RGGI with \$25 Carbon Price on Electricity

7C. Employment, All Industries

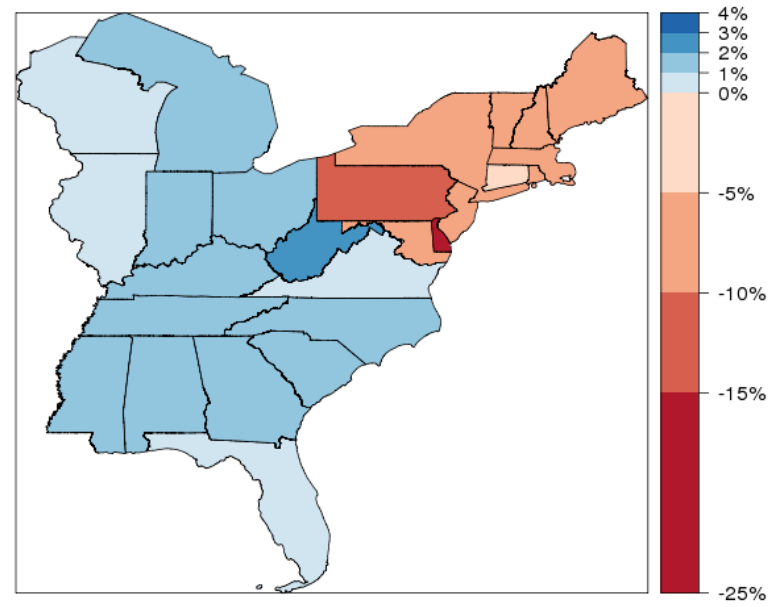

7D. Employment, High-Energy Industries

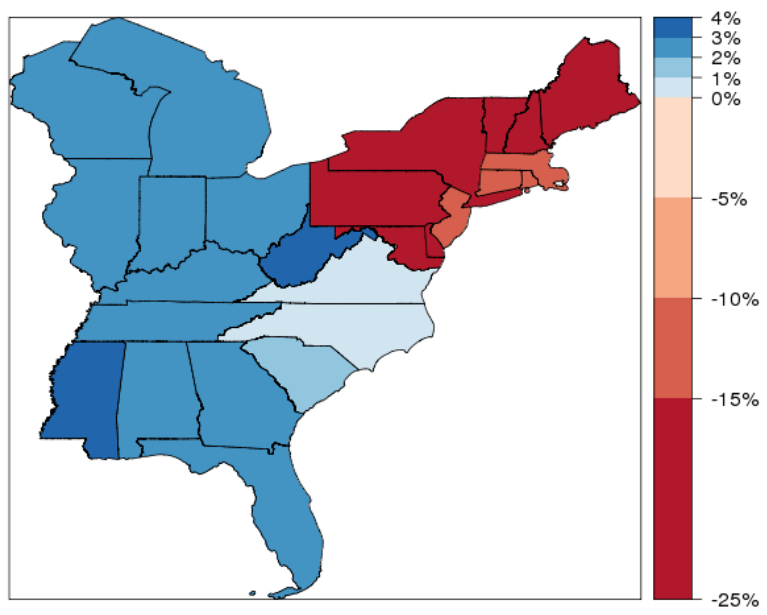

Notes: Change in average employment comparing no-policy ( $\$ 0$ carbon price) with a $\$ 25$ carbon price applied to electricity prices faced by all plants located in the RGGI region as well as Pennsylvania and New Jersey. Results shown separately for all manufacturing and high-energy industries (Groups 5-8 in Table 1). 